\title{
CARACTERÍSTICAS PRODUTIVAS E QUALITATIVAS DO ESTILOZANTES CAMPO GRANDE SUBMETIDO AO ESTRESSE SALINO
}

\author{
Delfran Batista dos Santos ${ }^{1 *}$; Tadeu Vinhas Voltolini ${ }^{2}$; Roberta Machado Santos ${ }^{3}$, Delka \\ Oliveira Azevedo ${ }^{1}$, Rogério Gonçalves Oliveira ${ }^{3}$, Elio Celestino de Oliveira Chagas ${ }^{4}$, \\ Florisvaldo Mesquita dos Santos ${ }^{1}$, Daniel Maia Nogueira ${ }^{2}$
}

RESUMO: O semiárido é caracterizado pela frequência de longas estiagens, tornando assim, os sistemas de produção dessa região bastante vulneráveis. Diante dessa ressalva e da vocação pecuária do semiárido brasileiro, este trabalho teve por objetivo avaliar o efeito da salinidade da água de irrigação sobre as características produtivas e qualitativas do estilosantes Campo Grande cultivado em ambiente protegido no semiárido baiano. O delineamento experimental foi inteiramente casualizado com sete níveis de salinidade da água de irrigação $(0,03 ; 0,55$; 1,$08 ; 1,70 ; 2,62 ; 3,52$ e $5,0 \mathrm{dS} \mathrm{m}^{-1}$ ) e três repetições. Concluiu-se que a composição bromatológica do estilosantes Campo Grande foi afetada pelo aumento da salinidade de água de irrigação e o aumento da salinidade na água de irrigação reduz a massa fresca de forragem, os teores de matéria orgânica e proteína bruta e aumenta o teor de minerais do estilosantes Campo Grande.

Palavras-chave: água salina, forragem, semiárido.

\section{PRODUCTIVITY AND QUALITY CHARACTERISTICS OF STYLOSANTHES SUBJECTED TO SALT STRESS}

\begin{abstract}
The semiarid region is characterized by the frequency of long droughts, thus making the production systems of the region very vulnerable. Given this caveat and the vocation of farming Brazilian semiarid region, this study aimed to evaluate the effect of irrigation water salinity on the productivity and quality characteristics of Stylosanthes Campo Grande grown in the semiarid region of Bahia. The experimental design was completely randomized with seven salinity levels of irrigation water $\left(0.03,0.55,1.08,1.70,2.62,3.52\right.$ and $\left.5.0 \mathrm{dS} \mathrm{m}^{-1}\right)$ and three replicates. From the results it was concluded that: the chemical composition of the Stylosanthes Campo Grande was affected by increasing salinity of irrigation water and the increase of salinity in irrigation water reduces the mass of fresh fodder, organic matter and crude protein and enhances the mineral content of the Stylosanthes Campo Grande.
\end{abstract}

Key-words: saline water, forage, semiarid.

\footnotetext{
${ }^{1}$ Instituto Federal Baiano, Campus Senhor do Bonfim, km 04 da Estrada da Igara, s/n, Zona Rural, CEP 48970000, Senhor do Bonfim-BA, Brasil. Caixa-Postal: 55. Fone: (74) 3541-3676. *E-mail: delfran.batista@gmail.com. Autor para correspondência.

${ }^{2}$ Pesquisadores da Empresa Brasileira de Pesquisa Agropecuária, Embrapa Semiárido, Petrolina, PE.

${ }^{3}$ Universidade Federal do Vale do São Francisco.

${ }^{4}$ Instituto Federal de Educação, Ciência e Tecnologia do Sertão Pernambucano.
}

Recebido em: 22/11/2012. Aprovado em: 05/05/2014.

Gl. Sci Technol, Rio Verde, v. 07, n. 02, p.1 - 7, maio/ago. 2014. 


\section{INTRODUÇÃO}

A baixa precipitação e a alta evaporação na região semiárida são fatores que contribuem para a ocorrência de solos salinos e sódicos, os quais representam em nível nacional aproximadamente $160.000 \mathrm{~km}^{2}$ ou 2\% do território brasileiro (GHEYI et al., 2010). Nessas condições, os sais não são lixiviados, acumulando-se no solo em quantidades prejudiciais ao crescimento normal das plantas (TAVARES FILHO et al., 2012).

No entanto, no semiárido brasileiro, onde as terras são mais intensamente cultivadas com o uso da irrigação, aumentamse ainda mais, o risco de tornar os solos salinizados e/ou alcalinizados (MIRANDA et al., 2011), refletindo diretamente em prejuízos socioeconômicos. Nessa região, também é comum a presença de água superficial e subterrânea com elevados teores de sais, o que limita sua utilização para a dessedentação humana e animal, seu uso doméstico e também para irrigação.

Culturas irrigadas com água salina podem sofrer restrições na absorção de água e nutrientes, e até mesmo alterar a expressão gênica, comprometendo assim a sua produtividade (RUBIO et al., 2011; MEDEIROS, 2011). Portanto, grandes são os desafios que os agricultores e pecuaristas enfrentam para produzir alimentos a partir de águas superficiais e subterrâneas com elevados teores de sais.

Pesquisas apontam que espécies forrageiras do gênero Atriplex apresentam-se como alternativa, porém, os estudos vêm se expandindo e alguns autores (GONZALEZ et al., 2000; QUECINI et al., 2002) já sinalizam os gêneros Brachiaria, Panicum e Estilosantes como outras possibilidades a serem exploradas em áreas com elevados teores de sais.

Diante desse cenário, onde o grande limitante à produção de alimentos está relacionado a disponibilidade hídrica (quantidade e qualidade) e a quantidade de forragem produzida, o uso de água salina para produção de forragem se torna um poderoso instrumento de apoio para convivência com a seca, visto que, fontes de águas com elevados teores de sais são comumente encontradas no semiárido, e pouco são utilizadas para fins agropecuários.

Portanto, este trabalho teve por objetivo avaliar o efeito da salinidade da água de irrigação sobre as características produtivas e qualitativas do estilosantes Campo Grande cultivado em ambiente protegido no semiárido baiano.

\section{MATERIAL E MÉTODOS}

$\mathrm{O}$ experimento foi conduzido em ambiente protegido na área do Instituto Federal Baiano (IF Baiano), Campus Senhor do Bonfim, Bahia, Brasil, no período de 10.12.2009 a 20.02.2010, a área experimental possui altitude média de $520 \mathrm{~m}$, e apresenta as seguintes coordenadas geográficas: latitude $10^{\circ} 27^{\prime} 46^{\prime}$ 'S , longitude $40^{\circ} 11^{\prime} 27^{\prime \prime} \mathrm{W}$.

Como material vegetal, utilizou-se sementes de estilosantes Campo Grande, híbrido resultante do Stylosanthes capitata e $S$. macrocephala, adquirida na Embrapa Semiárido.

Foram utilizados 21 recipientes para a semeadura. Estes recipientes foram confeccionados de tubos de PVC com $15 \mathrm{~cm}$ de diâmetro e $21 \mathrm{~cm}$ de altura, cuja extremidade inferior foi vedada com lona de polietileno vulcanizada e amarrada ao tubo com barbante. No centro da lona efetuou-se um orifício de $1 \mathrm{~cm}$ de diâmetro para a instalação de um pedaço de mangueira de 32 $\mathrm{mm}$ e $70 \mathrm{~cm}$ de comprimento que foi utilizada como dreno.

Os recipientes com volume de 3.711 $\mathrm{cm}^{3}$ foram preenchidos com solo do tipo Latossolo Amarelo, classificado de acordo as premissas da Embrapa (2006), coletado a uma profundidade de 0 a $20 \mathrm{~cm}$, da área experimental do IF Baiano, e cujas características estão discriminadas na Tabela 1. 
Tabela 1. Características químicas do Latossolo Amarelo utilizado para preenchimento dos recipientes

\begin{tabular}{lcc}
\hline Atributo & Unidade & Resultado \\
\hline Matéria Orgânica (M.O) & $\mathrm{g} \mathrm{kg}^{-1}$ & 24,8 \\
pH (H $\mathrm{H}_{2}$ ) $1: 2,5$ & & 7,1 \\
Extrato de saturação (CE) & $\mathrm{dS} \mathrm{m}^{-1}$ & 4,6 \\
Fósforo (P) & $\mathrm{mg} \mathrm{dm}^{-3}$ & 244,8 \\
Potássio (K) & $\mathrm{cmolc} \mathrm{dm}^{-3}$ & 1,3 \\
Cálcio (Ca) & $\mathrm{cmolc} \mathrm{dm}^{-3}$ & 2,2 \\
Magnésio (Mg) & $\mathrm{cmolc} \mathrm{dm}^{-3}$ & 2,8 \\
Sódio (Na) & $\mathrm{cmolc} \mathrm{dm}^{-3}$ & 0,72 \\
Alumínio (Al) & $\mathrm{cmolc} \mathrm{dm}^{-3}$ & 0 \\
Alumínio + Hidrogênio (H+Al) & $\mathrm{cmolc} \mathrm{dm}^{-3}$ & 1,15 \\
Soma de bases (SB) & $\mathrm{cmolc} \mathrm{dm}^{-3}$ & 7,02 \\
Capacidade de troca cationica (CTC) & $\mathrm{cmolc} \mathrm{dm}^{-3}$ & 8,2 \\
Saturação de bases (V) & $\%$ & 86 \\
Cobre (Cu) & $\mathrm{mg} \mathrm{dm}^{-3}$ & 1,93 \\
Ferro (Fe) & $\mathrm{mg} \mathrm{dm}^{-3}$ & 47,6 \\
Manganês (Mn) & $\mathrm{mg} \mathrm{dm}^{-3}$ & 106 \\
Zinco (Zn) & $\mathrm{mg} \mathrm{dm}^{-3}$ & 15,6 \\
\hline
\end{tabular}

Posteriormente, os recipientes foram que ficavam assentadas na superfície do solo, dispostos em uma bancada de madeira de 80 com objetivo de coletar a água de drenagem $\mathrm{cm}$ de altura com os drenos dos recipientes (Figura 1). conectados a garrafas PET's de dois litros

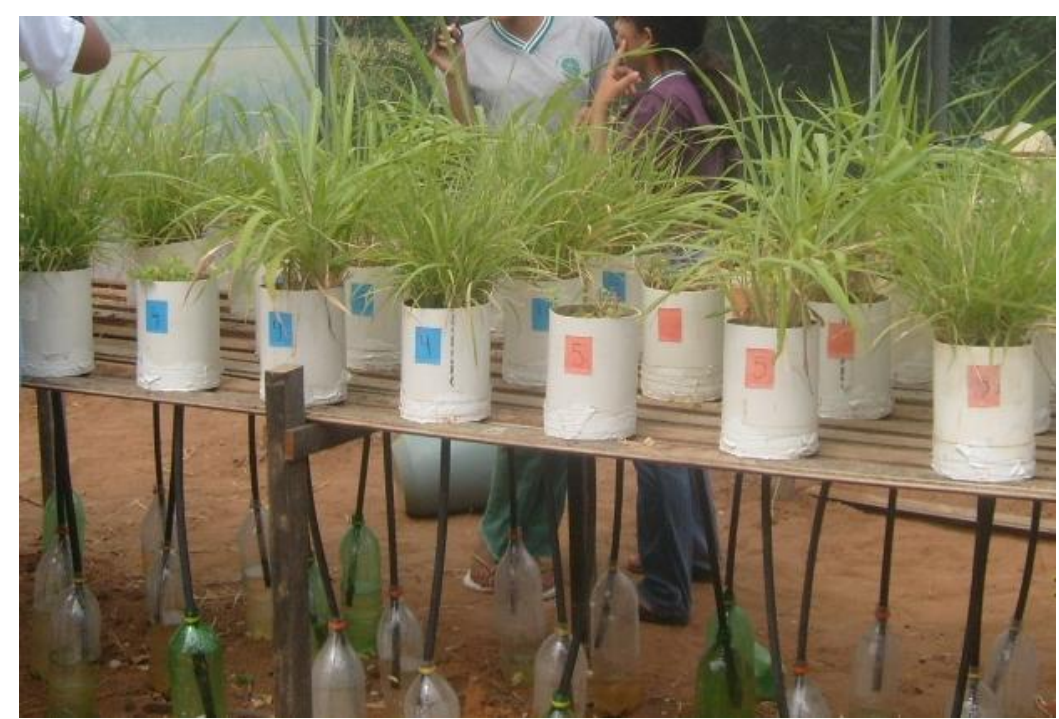

Figura 1. Detalhe da bancada com os recipientes e os drenos conectados as garrafas PET's

As sementes das forrageiras foram alternância dos recipientes, simulando um semeadas em cada recipiente separadamente, sistema do tipo consorcio com o capim seguindo a recomendação da Embrapa Gado Marandu (Brachiaria brizantha cv. Marandu), de Corte (2012) colocando uma camada de a fim de simular o sombreamento que ocorre solo de $2 \mathrm{~cm}$ sobre as sementes. A semeadura em condição real em campo (Figura 1). Foi do estilozantes foi realizada em esquema de realizada uma adubação de fundação com 
composto orgânico na proporção de 10 ton $\mathrm{ha}^{-1}$.

O delineamento experimental utilizado foi inteiramente casualizado com sete níveis de salinidade da água de irrigação $\left(0,03 ; 0,55 ; 1,08 ; 1,70 ; 2,62 ; 3,52\right.$ e $5,0 \mathrm{dS} \mathrm{m}^{-}$ ${ }^{1}$ ) e três repetições.

As medições da condutividade elétrica da água de irrigação foram realizadas em laboratório, por meio de um condutivímetro portátil Tecnopon, modelo mCA $150 \mathrm{P}$.

Até o décimo dia após a germinação o estilozantes foi irrigado com água pluvial; só então a partir dessa data, que se iniciaram as irrigações com as águas com diferentes níveis de sais dos tratamentos. Durante todo o experimento, a temperatura e umidade relativa foram monitoradas através de um medidor e registrador de temperatura e umidade relativa, instalado junto à bancada experimental.

O manejo das irrigações foi realizado, utilizando turno de rega fixo de dois dias, sendo o volume de água aplicado estimado em função da demanda evapotranspirométrica local. Tomava-se o cuidado em cada irrigação, que o solo retornasse a capacidade de campo, isso era verificado em função da drenagem observada nos vasos.

Com auxílio de tesouras de poda realizou-se o corte da forrageira aos 60 dias após o início da aplicação dos tratamentos (antes da floração) e teve como referência o comprimento do pseudocolmo a $5 \mathrm{~cm}$ acima da superfície do solo. Em seguida, as amostras coletadas foram acondicionadas em sacos de papel, devidamente identificadas, pesadas em balança de precisão e encaminhadas para o Laboratório de Nutrição Animal da Embrapa Semiárido, Petrolina PE, para realização das análises bromatológicas.

As amostras foram levadas a estufa de circulação de ar forçado a $55{ }^{\circ} \mathrm{C}$ por 72 horas e posteriormente moídas em moinhos tipo
"Willey" com peneiras de malhas de $1 \mathrm{~mm}$. As amostras de forragem analisadas para a determinação dos teores de matéria seca (MS), massa fresca (MF), matéria mineral (MM), matéria orgânica (MO), fibra em detergente neutro (FDN), fibra em detergente ácido (FDA) e proteína bruta (PB), foram realizadas segundo a metodologia recomendada por Silva e Queiroz (2002).

Os dados foram submetidos à análise de variância e, posteriormente, a regressão linear, considerando com diferença significativa valores de probabilidade inferiores a $5 \% \quad(\mathrm{P}<0,05)$. As análises estatísticas foram realizadas pelo programa Statistical Analyses System - SAS (1999).

\section{RESULTADOS E DISCUSSÃO}

A condição climática durante o período experimental reveste-se de importância ao analisar os resultados, pois as respostas morfofisiológicas das culturas dependem das condições ambientais. Com relação aos valores de temperatura média diária, observou-se que durante o período de condução do experimento, o regime térmico apresentou oscilação com valores médios diários, variando entre 19 a $42{ }^{\circ} \mathrm{C}$, sendo que a média geral para o período em observação foi de $26{ }^{\circ} \mathrm{C}$. A umidade relativa média oscilou entre 17 a $91 \%$, sendo que a média geral para o período foi de $49 \%$. A lâmina total acumulada durante o experimento foi em torno de $295 \mathrm{~mm}$. As condições ambientais proporcionadas na pesquisa estão em concordância com as apresentadas por Andrade et al. (2010).

A água salina utilizada nas irrigações foi preparada, diluindo-se a água salina coletada do açude Soein, situado no distrito da Igara, município de Senhor do Bonfim, Bahia, com água pluvial até atingir uma variação da condutividade elétrica de $0,55 \mathrm{dS}$

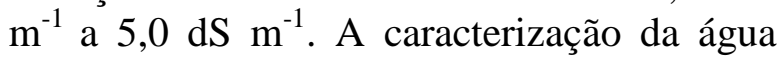
dos tratamentos encontra-se na Tabela 2. 
Tabela 2. Características químicas das águas utilizadas na irrigação das forrageiras.

\begin{tabular}{|c|c|c|c|c|c|c|c|c|}
\hline Atributo & Unidade & & & & Result: & & & \\
\hline Tratamentos & & $\mathrm{T} 1$ & $\mathrm{~T} 2$ & T3 & $\mathrm{T} 4$ & T5 & T6 & $\mathrm{T} 7$ \\
\hline Cálcio & $\operatorname{mmol}_{\mathrm{c}} \mathrm{L}^{-1}$ & 0,1 & 0,7 & 1,6 & 2,7 & 3,9 & 4,9 & 6,3 \\
\hline Magnésio & $\operatorname{mmol}_{\mathrm{c}} \mathrm{L}^{-1}$ & 0,1 & 2,1 & 4,1 & 5,5 & 9,5 & 12,4 & 18,7 \\
\hline Sódio & $\operatorname{mmol}_{\mathrm{c}} \mathrm{L}^{-1}$ & 0,06 & 2,20 & 4,10 & 5,90 & 10,20 & 13,80 & 20,80 \\
\hline Potássio & mmol $_{\mathrm{c}} \mathrm{L}^{-1}$ & 0,03 & 0,09 & 0,31 & 0,35 & 0,40 & 0,40 & 0,90 \\
\hline Soma de Bases (CTC) & $\operatorname{mmol}_{c} L^{-1}$ & 0,29 & 5,09 & 10,11 & 15,45 & 24 & 31,50 & 46,70 \\
\hline Bicarbonatos & $\operatorname{mmol}_{\mathrm{c}} \mathrm{L}^{-1}$ & 0,20 & 0,30 & 0,60 & 0,70 & 0,60 & 0,90 & 0,70 \\
\hline Sulfatos & $\mathrm{mmol}_{\mathrm{c}} \mathrm{L}^{-1}$ & 0,01 & 0,26 & 0,3 & 0,60 & 1,30 & 1,70 & 2,11 \\
\hline Cloretos & $\operatorname{mmol}_{\mathrm{c}} \mathrm{L}^{-1}$ & 0,10 & 4,80 & 9,60 & 14 & 22 & 30,00 & 43 \\
\hline Soma de anions (CTA) & $\operatorname{mmol}_{\mathrm{c}} \mathrm{L}^{-1}$ & 0,31 & 5,36 & 10,50 & 15,30 & 23,90 & 32,60 & 45,81 \\
\hline $\mathrm{pH}$ & & 6,3 & 5,8 & 6,4 & 6,4 & 6,5 & 6,9 & 6,5 \\
\hline $\mathrm{CE}$ & $\mathrm{dS} \mathrm{m}^{-1}$ & 0,03 & 0,55 & 1,08 & 1,70 & 2,62 & 3,52 & 5,0 \\
\hline RAS & $\left(\mathrm{mmol}_{\mathrm{c}} \mathrm{L}^{-1}\right)^{0,5}$ & 0,19 & 1,86 & 2,43 & 2,76 & 3,94 & 4,69 & 5,89 \\
\hline
\end{tabular}

$\mathrm{CE}=$ Condutividade elétrica do extrato de saturação do solo; RAS = Razão de adsorção de sódio.

Segundo Ayers e Westcoy (1999), os resultados apresentados na Tabela 2 sugere que quanto ao risco de causar salinização do solo essas águas podem ser classificadas como: nenhum risco de problema de salinização (T1 e T2), moderado risco de salinização (T3, T4 e T5) e severo risco de salinização (T6 e T7). Quanto a problemas de infiltração de água no solo causados pela sodicidade, essas podem ser classificadas como: sem risco de sodicidade (T5, T6 e T7), crescente risco de sodicidade (T2, T3 e T4) e severo risco de sodicidade (T1), seguindo a metodologia proposta por Ayers e Westcoy (1999).

Observa-se (Tabela 3) que o estilosantes Campo Grande sofreu influência dos níveis de salinidade da água de irrigação, sob os teores de MF, MM, MO e PB $(\mathrm{P}<0,05)$. Os teores de MS, FDN e FDA não foram afetados pela salinidade da água $(\mathrm{P}>0,05)$.

Tabela 3. Composição bromatológica do Estilosantes Campo Grande (Stylosanthes capitata e Stylosanthes macrocephala) cultivado sob diferentes níveis de salinidade da água de irrigação.

\begin{tabular}{lcccccccccc}
\hline Item & T1 & T2 & T3 & T4 & T5 & T6 & T7 & ER & $\mathrm{R}^{2}$ & CV \\
\hline MF & 89,9 & 98,1 & 115,5 & 109,0 & 65,2 & 72,4 & 64,0 & $\mathrm{Y}=105,52-8,59 x$ & 0,52 & 21,0 \\
MS & 23,54 & 19,78 & 24,1 & 21,41 & 25,69 & 31,15 & 56,54 & $\mathrm{~ns}$ & - & 32,1 \\
MM & 6,65 & 7,13 & 7,47 & 7,75 & 10,33 & 15,29 & 8,78 & $\mathrm{Y}=5,78+1,79 x$ & 0,43 & 34,4 \\
MO & 93,35 & 92,87 & 92,53 & 92,25 & 89,67 & 84,71 & 91,22 & $\mathrm{Y}=94,22-1,99 x$ & 0,43 & 3,1 \\
FDN & 46,16 & 43,7 & 46,02 & 30,04 & 42,48 & 44,10 & 56,09 & $\mathrm{~ns}$ & - & 19,5 \\
FDA & 37,33 & 36,96 & 36,96 & 36,45 & 32,93 & 38,11 & 48,1 & $\mathrm{~ns}$ & - & 13,1 \\
PB & 22,63 & 20,92 & 21,67 & 21,47 & 17,23 & 14,37 & 9,7 & $\mathrm{Y}=23,35-1,52 x$ & 0,38 & 11,3
\end{tabular}

$\mathrm{MF}=$ Massa fresca, $\mathrm{MS}=$ Matéria seca $(\%$ do alimento), $\mathrm{MM}=$ Matéria mineral, $\mathrm{MO}=$ matéria orgânica, $\mathrm{FDN}$ $=$ Fibra em detergente neutro, $\mathrm{FDA}=$ Fibra em detergente ácido, $\mathrm{PB}=$ proteína bruta. $\mathrm{ns}=$ não significativo $(\mathrm{P}>0,05)$.

$\mathrm{O}$ valor de $\mathrm{MM}$ aumentou linearmente em função do aumento da CE da água de irrigação (Tabela 3), apresentando um aumento de $12,2 \%$, por acréscimo unitário da
CE da água de irrigação no intervalo em estudo, enquanto os valores de MF, MO e PB diminuíram linearmente em função do aumento da CE da água de irrigação, 
apresentando uma redução de 8,2, 2,1 e 6,5\% respectivamente por acréscimo unitário da $\mathrm{CE}$ da água de irrigação no intervalo em estudo.

O aumento da concentração de minerais (MM) nas folhas do estilosantes pode ser atribuído, devido a uma quantidade maior de minerais na água em decorrência do aumento da salinidade, proporcionando aumento na concentração de sais na solução do solo, possibilitando assim, um aumento na absorção das plantas e, sobretudo, um aumento na incorporação de minerais nos tecidos vegetais.

Também o aumento da quantidade de minerais nos tecidos altera a produção de matéria orgânica, ou seja, o excesso de sais minerais presentes dificulta a atividade enzimática, promovendo desta forma uma diminuição na produção de matéria orgânica. Para Silva et al. (2011), uma maior concentração de cloreto de sódio poderá provocar danos fotossintéticos causados tanto por limitações estomáticas como por limitações bioquímicas, afetando diretamente a produção de carboidratos necessários para sustentar o crescimento da planta.

A redução nos teores de PB apresentada nesse estudo para o estilosantes pode estar relacionada com diminuições na absorção de nutrientes pelos vegetais e no metabolismo das plantas. Segundo Golena et al. (2004), ao avaliarem a influência do $\mathrm{NaCl}$ nos sistemas isoenzimáticos durante o estádio inicial da germinação do Stylosanthes guianensis, observaram que o estresse salino pode promover a perda da atividade de determinadas enzimas.

Observou-se também (Tabelas 3) que mesmo aumentando a concentração de sais na água de irrigação, não houve alterações significativas nas concentrações de MS, FDN e FDA, entretanto, sua turgescência foi comprometida, fato esse, comprovado pela redução significativa da MF à medida que aumenta os níveis de sais na água de irrigação. Essa resposta pode ser atribuída à baixa disponibilidade de água no solo em função da redução do potencial osmótico, ocasionando a redu- ção da expansão e do alongamento celular, devido ao decréscimo da turgescência.

\section{CONCLUSÕES}

A composição bromatológica do estilosantes Campo Grande foi afetada pelo aumento da salinidade de água de irrigação.

O aumento da salinidade na água de irrigação reduz a massa fresca de forragem e os teores de matéria orgânica e proteína bruta, ademais, houve um aumento do teor de minerais do estilosantes Campo Grande.

\section{AGRADECIMENTOS}

A Embrapa Semiárido e ao Instituto Federal Baiano pelo apoio na instalação e execução da pesquisa e ao CNPq através do edital 35/2010, processo n. 562867/2010-4.

\section{REFERÊNCIAS}

ANDRADE, C. M. S.; ASSIS, G. M. L. de; SALES, M. F. L. Estilosantes Campo Grande: leguminosa forrageira recomendada para solos arenosos do Acre. Rio Branco: Embrapa Acre, 2010.

AYERS, R. S.; WESTCOT, D. W. A qualidade da água na agricultura. Estudos, Irrigação Drenagem FAO 29 Campina Grande: UFPB. 1999.

EMBRAPA GADO DE CORTE. Disponível em:

http://www.cnpgc.embrapa.br/produtoseservi cos/pdf/Zimmer1SBZ2005.pdf. Acesso em: 10 de novembro de 2012.

EMPRESA BRASILEIRA DE PESQUISA AGROPECUÁRIA - EMBRAPA. Centro Nacional de Pesquisa de Solos. Sistema brasileiro de classificação de solos. Rio de Janeiro, 2006.

GHEYI, H.R.; DIAS, N. da S.; LACERDA, C.F. Manejo da salinidade na agricultura: Estudos básicos e aplicados. Fortaleza: INCT Sal, 2010. 

GONELA, A.; LEMOS, E.G.M.; S.L.F.; VIÉGAS, R.A.; SILVEIRA, J.A.G. RODRIGUES, T.J.D.; PATERNIANI, Salt stress induced damages on the M.L.S. Reação enzimática ao estresse salino photosynthesis of physic nut young plants. durante a germinação de estilosantes. Scientia Agricola, v. 68, n.1, p. 62-68, 2011. Pesquisa Agropecuária Brasileira,v.39, n.1, p.93-95, 2004.

GONZALEZ, L.M.; LOPEZ, R.C.; FONSECA, I.; RAMIREZ, R. Growth, stomatal frequency, DM yield and accumulation of ions in nine species of grassland legumes grown under salts conditions. Pastos y Forrajes, v.4, p.299308, 2000.

MEDEIROS, D.C. de; MEDEIROS, J.F. de; PEREIRA, F.A. de L; SILVA, S.C. de M.; AMÂNCIO, M. das G. Production and quality of melon hybrid Mandacaru irrigated with different levels of salinity. Horticultura Brasileira, v.29, n.4, p.600-604, 2011.

MIRANDA, M.A.; OLIVEIRA, E.E.M. de; SANTOS, K.C.F. dos; FREIRE, M.B.G. dos S.; ALMEIDA, B.G. de. Condicionadores químicos e orgânicos na recuperação de solo salino-sódico em casa de vegetação. Revista Brasileira de Engenharia Agrícola e Ambiental, v. 15, n. 5, p. 484-490, 2011.

QUECINI, V.M.; OLIVEIRA, C.A. de; ALVES, A.C.; VIEIRA, M.L.C. Factors influencing electroporation-mediated gene transfer to Stylosanthes guianensis (Aubl.) Sw. protoplasts. Genetics and Molecular Biology, v.25, p.73-80, 2002.

RUBIO, J.S; PEREIRA, W.E.; GARCIASANCHEZ, F.; MURILLO, L.; GARCÍA, A.L.; MARTÍNEZ, V. Sweet pepper production in substrate in response to salinity, nutrient solution management and training system. Horticultura Brasileira, v. 29, n. 3, p. 275-281, 2011.

SILVA, D.J.; QUEIROZ, A.C. Análise de alimentos (métodos químicos e biológicos). Viçosa: Universidade Federal de Viçosa, 2002.

STATISTICAL ANALYSES SYSTEM SAS. SAS/STATTM. SAS user's guide for windows environment. version 6. Cary: 1999.

TAVARES FILHO, A.N.; BARROS, M. de F.C.; ROLIM, M.M.; SILVA, Ê.F. de F. Incorporação de gesso para correção da salinidade e sodicidade de solos salinosódicos. Revista Brasileira de Engenharia Agrícola e Ambiental, v.16, n.3, p. 247-252, 2012. 